\title{
End Functionalization by Ring Opening Polymerization: Influence of Reaction Conditions on the Synthesis of End Functionalized Poly(lactic Acid)
}

\author{
Luis P. Icart, ${ }^{a}$ Edson Fernandes, ${ }^{b}$ Lissette Agüero, ${ }^{c}$ Maelia Z. Cuesta, ${ }^{d}$ Dionisio Z. Silva, ${ }^{d}$ \\ Daniel E. Rodríguez-Fernández, ${ }^{a}$ Fernando G. Souza Jr., ${ }^{a}$ Luis Maurício T. R. Lima ${ }^{a}$ and \\ Marcos L. Dias*,e
}

\author{
${ }^{a}$ Faculdade de Farmácia, Centro de Ciências da Saúde, Universidade Federal do Rio de Janeiro, \\ 21941-902 Rio de Janeiro-RJ, Brazil \\ ${ }^{b}$ Centro de Ciência e Tecnologia, Centro Universitário Serra dos Órgãos, \\ 25964-004 Teresópolis-RJ, Brazil
}

${ }^{c}$ Centro de Biomateriales and ${ }^{d}$ Facultad de Química, Universidad de la Habana, La Habana, Cuba

eInstituto de Macromoléculas Professora Eloisa Mano, Centro de Tecnologia,

Universidade Federal do Rio de Janeiro, 21941-598 Rio de Janeiro-RJ, Brazil

\begin{abstract}
In this paper, chemical functionalization of poly(lactic acid) (PLA) was carried out by using of salicyl aldehyde (SAl) and salicylic acid (SAc) as co-initiators of ring opening polymerization (ROP). Two factorial designs $\left(2^{2}\right)$ were performed to evaluate the effects of the lactide/catalyst and co-initiator/catalyst molar ratios on the content of aldehyde or carboxylic acid end groups, thermal properties and molecular weight (Mw) of PLA. Tin(II) 2-ethylhexanoate was used as a catalyst. The co-initiator/catalyst molar ratio has a statistically significant influence on the polymer functionalization. The highest co-initiator/catalyst molar ratio of 12/1 allows the best aldehyde or carboxylic acid functionalization, independent on the lactide/catalyst molar ratio. On the other hand, the used lactide/catalyst and co-initiator/catalyst molar ratios did not show a statistically significant influence on the polymer thermal properties. Besides, co-initiator/catalyst molar ratio has a statistically significant influence on the polymer molecular weight. So, the highest co-initiator/ catalyst molar ratio used (12/1) in combination with the highest lactide/catalyst ratio (125/1) produced functionalized PLA with higher molecular weights.
\end{abstract}

Keywords: poly(lactic acid), ring opening polymerization, end group functionalized PLA, experimental design

\section{Introduction}

Bioresorbable polymers are those capable of being completely degraded in an aqueous environment in their corresponding monomers, which, in turn, undergo metabolic action of living organisms. ${ }^{1-8}$ Among these polymers, poly(lactic acid) (PLA), poly(glycolic acid) and their copolymers have been widely used in biomedical applications, especially in orthopedics and controlled drug release due to characteristics such as, biodegradation and biocompatibility. ${ }^{9-12}$

PLA can be synthesized in a wide range of molecular weights using two procedures: (i) direct polycondensation

*e-mail: mldias@ima.ufrj.br reaction of lactic acid that leads to the formation of products of low molecular weight; and (ii) polyaddition reaction by ring opening of lactides, in the presence of a metal catalyst and/or a co-initiator agent, producing high molecular weight polymers as well as generating functional end groups in the structure of PLA, which are required to the design of new biomacromolecules. ${ }^{13,14}$

Ring opening polymerization (ROP) allows the synthesis of end functionalized polylactones and polylactides of high molecular weight. ${ }^{6}$ These polyesters are formed when cyclic ester monomers are reacted with a catalyst and a co-initiator. ROP can be performed as bulk polymerization or in solution and the catalyst (also called initiator) is necessary to start the reaction. ${ }^{5,715}$ Besides, depending on the type of initiator, ROP proceeds according to three 
different major reaction mechanisms, cationic, anionic or coordination-insertion. By these procedures, functionalized polyesters of high-molecular weight and low polydispersity can be synthesized in short periods of time. ${ }^{12,16}$ Some limitations of polycondensation, such as the need for exact stoichiometry, high reaction temperatures and the removal of water, are excluded in ROP. ${ }^{16}$

Tin(II) 2-ethylhexanoate ( $\mathrm{SnOct}_{2}$ ) is a commonly used catalyst in ROP of lactones and lactides and is approved as additive by the Food and Drug Administration (FDA) for PLA applied in food packaging. ${ }^{17}$ By using this catalyst, polymerization reaction takes place by a coordination insertion mechanism in which monomer impurities containing hydroxyl groups act as co-initiators, reacting with $\mathrm{SnOct}_{2}$ to form a Sn-O alkoxide bond necessary to initiate the coordination-insertion of the monomer. ROP of lactides with $\mathrm{SnOct}_{2}$ is fairly slow and, for economic and commercial reasons, it is desirable to increase the rate of polymerization by addition of hydroxyl-functionalized compounds as co-initiator. ${ }^{18,19}$

Each macromolecule of PLA formed by the mechanism of coordination-insertion of ROP will generally contain one chain end terminated with a functional group originated from the termination reaction and another one distal end functional group coming from the co-initiator agent. By altering the co-initiator, the nature of the end functional groups can be varied to fit the application of the polymer. The type of co-initiator and end-group plays an important role in the thermal stability, hydrolytic stability and molecular weight of the resulting polyester. ${ }^{4,20}$ Thus, from these reactions, functional groups capable of allowing other PLA modification reactions can also be introduced into the polymer structure. This makes the polyester able to form active macromolecules by reaction of the end-functional groups with complementary groups that could be present in biologically active molecules or other polymeric system of interest. ${ }^{21,22}$ Therefore, applicability of PLA-based materials can be amplified if functional end groups are incorporated at the polymer backbone. ${ }^{4}$

For this reason, nowadays, many authors investigate the use of new ROP co-initiators aiming to generate a wide variety of functional groups into the polymer backbone that will contribute to the design and synthesis of new biologically active macromolecules for biomedical applications. ${ }^{23,24}$

It is our interest to study the functionalization of PLA by ROP in order to generate enough quantities of end functional groups in the polymer backbones available to participate in further syntheses of PLA based macromolecules of biopharmaceutical interest. Therefore, in this work, we show results that explain statistically the influence of some variables of ROP on the aldehyde and carboxylic acid co-initiators for the end functionalization of PLA.

\section{Experimental}

\section{Materials}

L-Lactide (L) (Puralact L, 99.5 wt.\%) was supplied by Purac. Tin(II) 2-ethylhexanoate $\left(\mathrm{Sn}(\mathrm{Oct})_{2}\right)$, salicyl aldehyde (SAl) and salicylic acid (SAc) were supplied by Aldrich. Toluene, chloroform, dichlorometane and ethyl alcohol were supplied by Vetec/Aldrich. All reactants were used as received, except $L$-lactide that was purified by crystallization from toluene.

\section{Polymerization}

Functionalized poly( $L$-lactide) (end-activated PLA) were obtained from $L$-lactide $(\mathrm{L})$ polymerization in a $0.250 \mathrm{~L}$ glass flask with magnetic stirring which could be maintained at the initial part of the polymerization. Lactide $(1 \mathrm{~g})$ was fed into the flask with the appropriate amount of co-initiator and $\mathrm{Sn}(\mathrm{Oct})_{2}$. The choice of co-initiator for each one of the polymerization was dependent on the requested chain end functional group. Salicyl aldehyde and salicylic acid were used as co-initiator. The investigated lactide/catalyst molar ratio $(\mathrm{R})$ and the co-initiator/catalyst molar ratio (r) were defined according to the proposed experimental design (see below). All the reactions were carried out at $180^{\circ} \mathrm{C}$ for $1 \mathrm{~h}$ under nitrogen atmosphere. After this time, the flask was rapidly cooled down to room temperature and its content dissolved in chloroform $(10 \mathrm{~mL})$. The solutions were kept under stirring for $2 \mathrm{~h}$ prior precipitation in cold ethanol $(100 \mathrm{~mL})$. The yields were calculated based on weight of monomer at the feed and precipitated polymer.

\section{Experimental design}

Two $2^{2}$ factorial designs with replicates at central point were developed to evaluate the effects of lactide/catalyst and co-initiator/catalyst molar ratios as independent variables on the aldehyde or carboxyl acid end functionalized PLA. The levels of each independent factor picked out and the correspondent matrix of experiments for each co-initiator are shown in Tables 1-3. In both factorial designs, experimental runs were carried out in duplicate and the central points in triplicate.

Also, the effect of the lactide/catalyst and co-initiator/ catalyst molar ratio on thermal properties and molecular weight of the synthesized end functionalized PLA was analyzed. For these purposes, each sample was characterized 
Table 1. Levels of the independent factor for the $2^{2}$ factorial design

\begin{tabular}{lccc}
\hline Independent factor & $\begin{array}{c}\text { Low } \\
\text { level }\end{array}$ & $\begin{array}{c}\text { Middle } \\
\text { level }\end{array}$ & $\begin{array}{c}\text { High } \\
\text { level }\end{array}$ \\
\hline Lactide/catalyst ratio $\left(\mathrm{X}_{1}\right)$ & 75 & 100 & 125 \\
Co-initiator/catalyst molar ratio $\left(\mathrm{X}_{2}\right)$ & 0 & 6 & 12 \\
\hline
\end{tabular}

Table 2. $2^{2}$ Factorial designs for the aldehyde end functionalized PLA study

\begin{tabular}{lcc}
\hline Experimental run & {$[\mathrm{L}] /\left[\mathrm{Sn}(\mathrm{Oct})_{2}\right]\left(\mathrm{X}_{1}\right)^{\mathrm{a}}$} & {$[\mathrm{SAl}] /\left[\mathrm{Sn}(\mathrm{Oct})_{2}\right]\left(\mathrm{X}_{2}\right)^{\mathrm{b}}$} \\
\hline 1 & -1 & -1 \\
2 & 1 & -1 \\
3 & -1 & 1 \\
4 & 1 & 1 \\
$\mathrm{PC}$ & 0 & 0 \\
\hline
\end{tabular}

a $[\mathrm{L}] /\left[\mathrm{Sn}(\mathrm{Oct})_{2}\right]$ : lactide/tin octoate concentration ratio; ${ }^{\mathrm{b}}[\mathrm{SAc}] /\left[\mathrm{Sn}(\mathrm{Oct})_{2}\right]$ : salicyl aldehyde/tin octoate concentration ratio; PC: central point.

Table 3. $2^{2}$ Factorial designs for the carboxylic acid end functionalized PLA study

\begin{tabular}{lcc}
\hline Experimental run & {$[\mathrm{L}] /\left[\mathrm{Sn}(\mathrm{Oct})_{2}\right]\left(\mathrm{X}_{1}\right)^{\mathrm{a}}$} & {$[\mathrm{SAc}] /\left[\mathrm{Sn}(\mathrm{Oct})_{2}\right]\left(\mathrm{X}_{2}\right)^{\mathrm{b}}$} \\
\hline 1 & -1 & -1 \\
2 & 1 & -1 \\
3 & -1 & 1 \\
4 & 1 & 1 \\
PC & 0 & 0
\end{tabular}

${ }^{\mathrm{a}}[\mathrm{L}] /\left[\mathrm{Sn}(\mathrm{Oct})_{2}\right]$ : lactide/tin octoate concentration ratio; ${ }^{[}[\mathrm{SAc}] /\left[\mathrm{Sn}(\mathrm{Oct})_{2}\right]$ : salicylic acid/tin octoate concentration ratio.

by thermogravimetric analysis (TGA), differential scanning calorimetry (DSC) and gel permeation chromatography (GPC) (see Material characterization section).

The effects of the independent factors and its interaction, for both factorial designs, can be described through the coefficients of the predicted response equation as follows:

$Y=\beta_{0}+\beta_{1} X_{1}+\beta_{2} X_{2}+\beta_{12} X_{1} X_{2}$

where $X_{1}$ is the independent factor lactide/catalyst molar ratio and $\mathrm{X}_{2}$ the co-initiator/catalyst molar ratio.

Experiments were made at random and 0.05 was considered as significance level. Statistical analyses were carried on employing software Statistica 7.0.

\section{Material characterization}

UV-Vis spectroscopy measurements of end functionalized PLA were performed in a Varian Cary 100 model UV-Vis spectrometer (concentration $0.1 \mathrm{wt.} / \mathrm{v} \%$ ) using dichloromethane as solvent and quartz cuvette $(1 \mathrm{~cm})$. Spectra were recorded from $200-400 \mathrm{~nm}$ with determination of the maximum absorbance of salicyl aldehyde and salicylic acid at 260 and $320 \mathrm{~nm}$, respectively. An analytical curve was made from 1.6 to $25.0 \mu \mathrm{g} \mathrm{mL}^{-1}$ and 1.0 to $25.0 \mu \mathrm{g} \mathrm{mL}^{-1}$ for salicyl aldehyde and salicylic acid, respectively. Analyses were carried out in triplicate to quantify them in the samples. In a typical procedure, a first solution of each co-initiator was prepared at a concentration of $1 \mathrm{mg} \mathrm{mL} \mathrm{mL}^{-1}$. Subsequently, a 100 -fold dilution was performed to obtain a second dichloromethane solution with concentration of approximately $10.0 \mu \mathrm{g} \mathrm{mL}-1$.

Nuclear magnetic resonance ( ${ }^{1} \mathrm{H}$ NMR) measurements were carried out in a Varian Mercury VX-300 NMR spectrometer operating at $300 \mathrm{MHz}$, temperature of acquisitions at $40{ }^{\circ} \mathrm{C}$, number of acquisitions of 20 , repetition time of pulses of $20 \mathrm{~s}$ and pulse-length of 9.40 (calibration for $\left.45^{\circ}\right)$. Samples $(15 \mathrm{mg}$ ) were dissolved in chloroform-D1 $(0.8 \mathrm{~mL})$ in $5 \mathrm{~mm}$ NMR tubes at room temperature.

GPC analysis of each end functionalized PLA was determined using an Agilent 1200 series HPLC with a Phenomenex linear Phenogel column. Chloroform was used as solvent with a flow rate of $1.0 \mathrm{~mL} \mathrm{~min}{ }^{-1}$. Monodisperse polystyrene standards were used as calibration and the molecular weights are expressed relatively to polystyrene molecular weights.

DSC analyses of end functionalized PLA were carried out in a TA Q1000 V9.9 Build 303 Calorimeter. Briefly, $5 \mathrm{mg}$ of the samples were heated and cooled at a rate of $10^{\circ} \mathrm{C} \mathrm{min}{ }^{-1}$ from -80 to $200^{\circ} \mathrm{C}$ under nitrogen flow. Values of glass transition $\left(\mathrm{T}_{\mathrm{g}}\right)$, melting temperature $\left(\mathrm{T}_{\mathrm{m}}\right)$ and the crystallization temperature on cooling $\left(\mathrm{T}_{\mathrm{cc}}\right)$ were taken from the second heating run followed by a cooling run.

TGA analyses of the end functionalized PLA were performed using a TA Instruments TGA Q500 Thermoanalyser. Measurements were carried out in nitrogen at a heating rate of $20^{\circ} \mathrm{C} \mathrm{min}^{-1}$ up to $700{ }^{\circ} \mathrm{C}$ with a gas flow rate of $20 \mathrm{~mL} \mathrm{~min}^{-1}$.

\section{Results and Discussion}

The use of two co-initiators, salicylic acid and salicyl aldehyde, for the synthesis of the aldehyde or carboxylic acid end functionalized PLA by ROP in the presence of $\mathrm{Sn}(\mathrm{Oct})_{2}$ as a catalyst was reported in a previous work of our group at a specific reaction condition. ${ }^{22}$ Coordinationinsertion is the mechanism by which these co-initiators enable the end functionalization of PLA (Figure 1).

Considering the usefulness of these co-initiators for the end functionalization of PLA, and its subsequent 

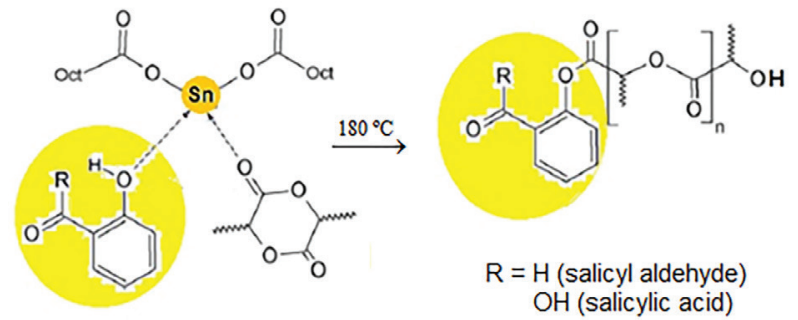

Figure 1. Synthesis of aldehyde and carboxylic acid end functionalized PLA by ring opening polymerization (ROP).

application for the design and synthesis of biologically active macromolecules, ${ }^{21,22}$ it was of our interest to study the relation between the co-initiator/catalyst and lactide/ catalyst molar ratio on the degree of end functionalization of
PLA. The effect of these variables on the thermal properties and molecular weight of the end functionalized PLA was also investigated.

Two factorial experimental designs $\left(2^{2}\right)$ with replicates at central point for each co-initiator were employed for those purposes. Both designs were duplicate at factorial points and the central points were triplicate. Experimental results are shown in Tables 4 and 5. As can be observed from the experimental data reported in Tables 4 and 5, the analysed independent factors (lactide/catalyst and co-initiator/catalyst molar ratio) influence the degree of end functionalization for both co-initiators (aldehyde or carboxylic acid), as well as, the thermal properties and the molecular weight of the synthesized PLA.

Table 4. Experimental results of the $2^{2}$ factorial designs for the SAl end functionalized PLA study

\begin{tabular}{|c|c|c|c|c|c|c|c|c|}
\hline Run & {$[\mathrm{L}] / \mathrm{Sn}(\mathrm{Oct})_{2}$} & {$[\mathrm{Sal}] / \mathrm{Sn}(\mathrm{Oct})_{2}$} & {$[\mathrm{Sal}] / \mathrm{ppm}$} & $\mathrm{T}_{\mathrm{d}} /{ }^{\circ} \mathrm{C}$ & $\mathrm{T}_{\mathrm{g}} /{ }^{\circ} \mathrm{C}$ & $\mathrm{T}_{\mathrm{m}} /{ }^{\circ} \mathrm{C}$ & $\mathrm{X}_{\mathrm{c}}{ }^{\mathrm{a}} / \%$ & $\mathrm{Mn} /\left(\mathrm{g} \mathrm{mol}^{-1}\right)$ \\
\hline $1 \mathrm{a}$ & -1 & -1 & 0.00 & 237.45 & 52.01 & 153.52 & 45.88 & 9,500 \\
\hline $2 \mathrm{a}$ & -1 & -1 & 0.00 & 258.88 & 55.33 & 159.26 & 48.02 & 8,700 \\
\hline $3 a$ & +1 & -1 & 0.00 & 248.12 & 55.76 & 159.92 & 47.74 & 23,700 \\
\hline $4 \mathrm{a}$ & +1 & -1 & 0.00 & 264.43 & 54.16 & 162.90 & 55.64 & 22,800 \\
\hline $5 \mathrm{a}$ & -1 & +1 & 6.96 & 255.76 & 56.17 & 158.34 & 52.28 & 11,800 \\
\hline $6 a$ & -1 & +1 & 5.60 & 254.67 & 56.70 & 161.52 & 57.79 & 15,300 \\
\hline $7 \mathrm{a}$ & +1 & +1 & 5.60 & 248.20 & 56.31 & 159.26 & 51.90 & 21,200 \\
\hline $8 a$ & +1 & +1 & 5.14 & 255.36 & 57.42 & 161.92 & 51.84 & 27,100 \\
\hline $9 \mathrm{a}$ & 0 & 0 & 5.16 & 251.94 & 51.70 & 154.84 & 43.38 & 8,000 \\
\hline $10 \mathrm{a}$ & 0 & 0 & 5.75 & 250.38 & 57.78 & 160.32 & 63.72 & 7,800 \\
\hline $11 \mathrm{a}$ & 0 & 0 & 6.20 & 249.21 & 56.83 & 163.55 & 57.20 & 7,500 \\
\hline
\end{tabular}

Sal: salicyl aldehyde; $\mathrm{T}_{\mathrm{d}}$ : temperature of maximum weigh lost rate; $\mathrm{T}_{\mathrm{g}}$ : glass transition temperature; $\mathrm{T}_{\mathrm{m}}$ : melting temperature; $\mathrm{X}_{\mathrm{c}}$ : degree of crystallinity;

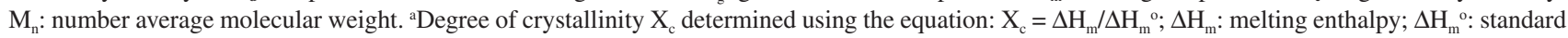
melting enthalpy for $100 \%$ crystalline PLA $\left(106 \mathrm{~J} \mathrm{~g}^{-1}\right) .^{25}$

Table 5. Experimental results of the $2^{2}$ factorial designs for the SAc end functionalized PLA study

\begin{tabular}{|c|c|c|c|c|c|c|c|c|}
\hline Run No. 2 & {$[\mathrm{~L}] / \mathrm{Sn}(\mathrm{Oct})_{2}$} & {$[\mathrm{SAc}] / \mathrm{Sn}(\mathrm{Oct})_{2}$} & {$[\mathrm{SAc}] / \mathrm{ppm}$} & $\mathrm{T}_{\mathrm{d}} /{ }^{\circ} \mathrm{C}$ & $\mathrm{T}_{\mathrm{g}} /{ }^{\circ} \mathrm{C}$ & $\mathrm{T}_{\mathrm{m}} /{ }^{\circ} \mathrm{C}$ & $\mathrm{X}_{\mathrm{c}}^{\mathrm{a}} / \%$ & $\mathrm{Mn} /\left(\mathrm{g} \mathrm{mol}^{-1}\right)$ \\
\hline $1 b$ & -1 & -1 & 0.00 & 238.65 & 49.56 & 158.93 & 51.99 & 5,900 \\
\hline $2 \mathrm{~b}$ & -1 & -1 & 0.00 & 240.25 & 48.21 & 157.93 & 53.60 & 11,900 \\
\hline $3 b$ & +1 & -1 & 0.00 & 243.71 & 48.10 & 158.91 & 51.82 & 22,600 \\
\hline $4 \mathrm{~b}$ & +1 & -1 & 0.00 & 246.00 & 47.50 & 157.18 & 51.31 & 22,800 \\
\hline $5 b$ & -1 & +1 & 11.94 & 242.09 & 47.08 & 156.29 & 42.88 & 15,500 \\
\hline $6 \mathrm{~b}$ & -1 & +1 & 13.28 & 249.40 & 49.30 & 157.46 & 40.91 & 12,100 \\
\hline $7 \mathrm{~b}$ & +1 & +1 & 9.63 & 256.37 & 49.68 & 159.23 & 63.62 & 27,100 \\
\hline $8 b$ & +1 & +1 & 10.24 & 255.36 & 50.66 & 160.74 & 65.02 & 18,800 \\
\hline $9 b$ & 0 & 0 & 10.67 & 248.97 & 48.58 & 159.87 & 63.60 & 13,100 \\
\hline $10 \mathrm{~b}$ & 0 & 0 & 10.23 & 242.21 & 50.92 & 162.69 & 65.10 & 14,900 \\
\hline $11 \mathrm{~b}$ & 0 & 0 & 9.91 & 248.29 & 49.89 & 160.53 & 62.10 & 10,900 \\
\hline
\end{tabular}

SAc: salicylic acid; $T_{d}$ : temperature of maximum weigh lost rate; $T_{g}$ : glass transition temperature; $T_{m}:$ melting temperature, $X_{c}:$ degree of crystallinity; $\mathrm{M}_{\mathrm{n}}$ : number average molecular weight. ${ }^{a}$ Degree of crystallinity $\mathrm{X}_{\mathrm{c}}$ determined using the equation: $\mathrm{X}_{\mathrm{c}}=\Delta \mathrm{H}_{\mathrm{m}} / \Delta \mathrm{H}_{\mathrm{m}}{ }^{\circ} ; \Delta \mathrm{H}_{\mathrm{m}}$ : melting enthalpy; $\Delta \mathrm{H}_{\mathrm{m}}{ }^{\circ}$ : standard melting enthalpy for $100 \%$ crystalline PLA $\left(106 \mathrm{~J} \mathrm{~g}^{-1}\right) .^{25}$ 

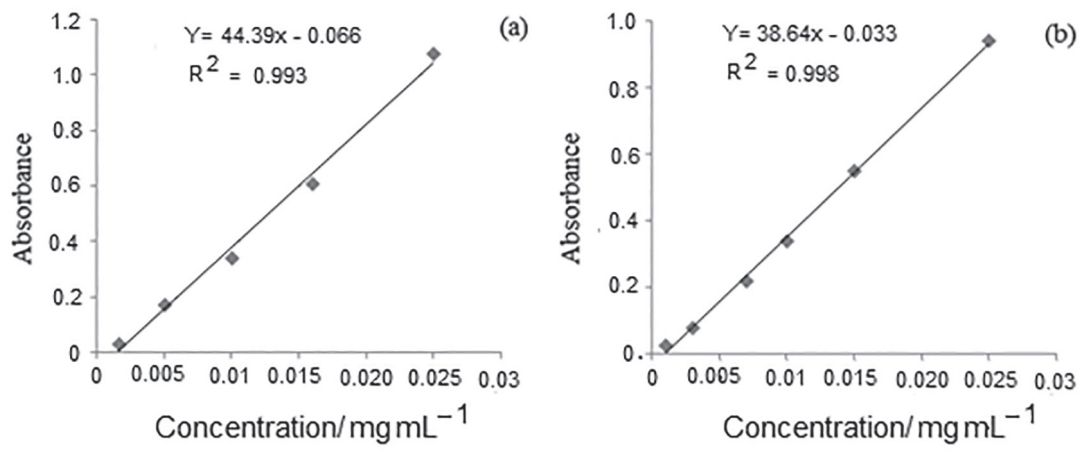

Figure 2. Calibration curves used to quantify (a) salicyl aldehyde and (b) salicylic acid.

Table 4 resumes the results for salicylic acid employed as co-initiator. It is possible to observe that the highest functionalization of PLA was reached at condition number five, in which the lactide/catalyst molar ratio was used at low level and the co-initiator/catalyst molar ratio was at high level. On the other hand, when co-initiator was not present in the medium, it was not detectable end functionalization of PLA (experiments 1-4).

Results for salicyl aldehyde showed similar tendency to that of salicylic acid (Table 5). However, the end carboxylic functionalization of PLA is twice that shown in Table 4 at the same condition.

The calibration curve used to quantify salicyl aldehyde and salicylic acid was obtained with a correlation coefficient $\left(\mathrm{R}^{2}\right)$ of 0.993 and 0.998 for each co-initiator, respectively (Figures 2a and 2b). Quantification of salicyl aldehyde and salicylic acid in the samples of PLA showed the success of PLA functionalization with carboxylic or aldehyde groups after ROP. Considering the mechanism of ROP, a hydroxyl functional group present in a co-initiator molecule reacts with $\mathrm{Sn}(\mathrm{Oct})_{2}$, forming the initiating tin alkoxide linkage necessary to propagate monomer addition. After termination, a fragment of the co-initiator remains at the end of the chain. These results are in agreement with those previously reported in the literature by the use of some aliphatic and aromatic alcohols as co-initiators of ROP. ${ }^{26-28}$

${ }^{1} \mathrm{H}$ NMR spectra of both aldehyde and carboxylic acid end functionalized PLA are shown in Figure 3. These spectra allow the identification of the structure of the co-initiators linked to the polymer backbone.

${ }^{1} \mathrm{H}$ NMR spectra of aldehyde (Figures 3a and 3a1) and carboxylic acid (Figure $3 \mathrm{~b}$ ) end functionalized PLA showed signals at $\delta 1.58$ and $5.19 \mathrm{ppm}$ due to $\mathrm{CH}_{3}$ and $\mathrm{CH}$ protons of PLA, respectively. In turn, the peak at $\delta 4.2 \mathrm{ppm}$ probably corresponds to the $\mathrm{CH}_{2}$ of $\mathrm{Sn}(\mathrm{Oct})_{2}$ still linked at the end of the chain. Examination of the microstructure of both end functionalized PLA by ${ }^{1} \mathrm{H}$ NMR revealed resonance signals between $\delta 7.0$ and $8.0 \mathrm{ppm}$ attributed to aromatic protons of salicyl aldehyde and salicylic acid, respectively (Figures 3a and $3 b$ ). The spectrum of aldehyde end functionalized PLA also showed a peak at $\delta 10.0 \mathrm{ppm}$ (Figure 3a1) attributed to the aldehyde proton of salicyl aldehyde covalently linked. Due to the lower molar ratio of these end functional groups in the polymer, they have poor contribution in protons, resulting mainly in peaks of small intensity in the spectra.

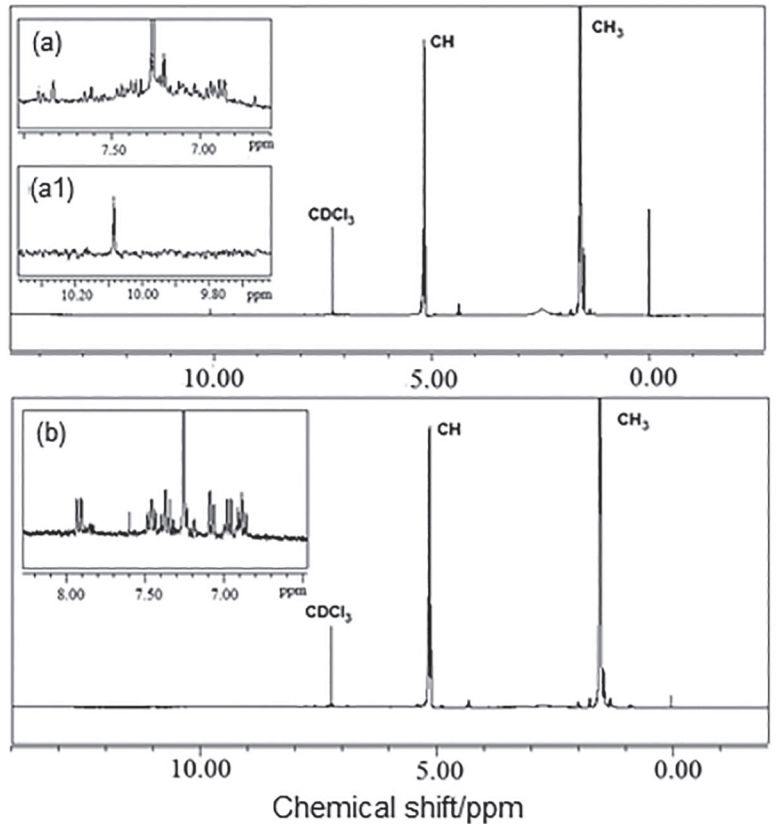

Figure 3. ${ }^{1} \mathrm{H}$ NMR spectra of (a) and (a1) carboxylic acid and (b) aldehyde end functionalized PLA.

In order to better understand the influence of the independent factors on the end functionalization of PLA, analyses of variance (ANOVA) were developed for each co-initiator, as shown in Tables 6 and 7.

In the factorial design, in which salicylic acid was employed as co-initiator (Table 6), the co-initiator/ catalyst molar ratio $\left(\mathrm{X}_{2}\right)$ was the independent factor with significant influence on the final aldehyde functionalization of PLA, while the independent factor lactide/catalyst molar ratio $\left(X_{1}\right)$ does not have any significant influence on the 
Table 6. Factor coefficient discrimination and lack of fit of the model adjusted corresponding to the factorial design $2^{2}$ employing salicylic acid (SAc) as co-initiator. Influence on the PLA functionalization

\begin{tabular}{lcc}
\hline Regression coefficient & Value & $p$-Value \\
\hline$\beta_{0}($ block effect) & 3.791818 & 0.00000001 \\
$\beta_{1}\left(X_{1}\right)^{\mathrm{a}}$ & -0.190000 & 0.298454 \\
$\beta_{2}\left(\mathrm{X}_{2}\right)^{\mathrm{a}}$ & 2.950000 & 0.000002 \\
$\beta_{12}\left(\mathrm{X}_{1} \mathrm{X}_{2}\right)^{\mathrm{a}}$ & -0.190000 & 0.298454 \\
Lack of fit $^{\mathrm{a}}$ & - & 0.000071 \\
\hline
\end{tabular}

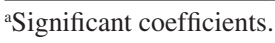

Table 7. Factor coefficient discrimination and lack of fit of the model adjusted corresponding to the factorial design $2^{2}$ employing SAl as co-initiator. Influence on the PLA functionalization

\begin{tabular}{lcc}
\hline Regression coefficient & Value & $p$-Value \\
\hline$\beta_{0}($ block effect) & 6.900 & 0.00000001 \\
$\beta_{1}\left(X_{1}\right)^{\mathrm{a}}$ & -0.669 & 0.007528 \\
$\beta_{2}\left(\mathrm{X}_{2}\right)^{\mathrm{a}}$ & 5.636 & 0.000001 \\
$\beta_{12}\left(\mathrm{X}_{1} \mathrm{X}_{2}\right)^{\mathrm{a}}$ & -0.669 & 0.007528 \\
Lack of fit $^{\mathrm{a}}$ & - & 0.000007 \\
\hline
\end{tabular}

aSignificant coefficients.

aldehyde functionalization of PLA. First order model obtained in this factorial design is described in equation 2 :

$\mathrm{Y}=3.79+2.95 \mathrm{X}_{2}$

For the factorial design employing salicyl aldehyde as co-initiator (Table 7), all independent factors and its interaction generated in this design have a significant influence on carboxylic functionalization of PLA. The obtained mathematical first order model was represented by equation 3 :

$\mathrm{Y}=6.90-0.67 \mathrm{X}_{1}+2.95 \mathrm{X}_{2}-0.67 \mathrm{X}_{1} \mathrm{X}_{2}$

The obtained model generated a response surface in the interval of each considered independent factor. Results of lactide/catalyst and co-initiator/catalyst molar ratio surface and contour of predicted functionalization ratio are shown in Figure 4.

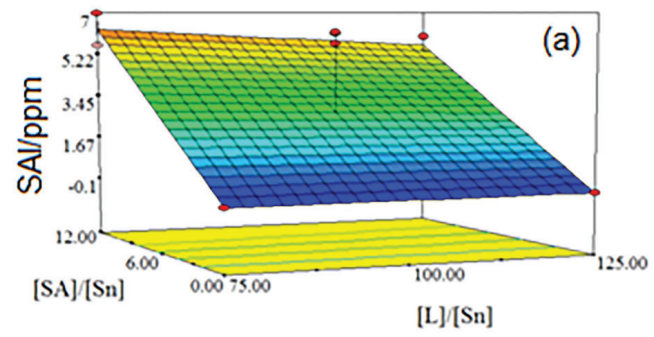

As can be observed from Figures $4 \mathrm{a}$ and $4 \mathrm{~b}$, aldehyde and carboxylic acid functionalizations of PLA were found to increase with the increment of the co-initiator/ catalyst molar ratio. Hence, aldehyde and carboxylic acid functionalizations were maximum at the highest level of co-initiator/catalyst molar ratio (12/1). However, aldehyde or carboxylic acid functionalization was not found to be influenced by changing the $[\mathrm{L}] /[\mathrm{Sn}]$ molar ratio from $75 / 1$ to $125 / 1$, which was also confirmed by the ANOVA analysis (Tables 6 and 7). Considering the mechanism of ROP described above, higher levels of co-initiator/catalyst molar ratio increase the probability of reaction between the catalyst and the co-initiator, stage necessary for the polymerization initiation. It is important to mention that other hydroxyl impurities, such as lactic acid and water could eventually begin the process of chain growth without any effect on the kinetic of ROP. This fact suggests that these impurities did not inhibit the syntheses of end functionalized PLA. ${ }^{29}$ Therefore, in ROP by coordination insertion mechanism, higher levels of co-initiator/catalyst molar ratio assure the presence of the co-initiator functional group in the polymer. The results are in agreement with those reported for the use of some different co-initiators in ROP. ${ }^{7,30-33}$ On the other hand, the model has a significant lack of fit for each co-initiator, indicating that is possible to be in an area where there is an optimal point.

In order to show the statistical influence of this dependent variables and its combination on the level of aldehyde or carboxylic acid functionalization of PLA, Pareto chart was plotted as shown in Figures $5 \mathrm{a}$ and $5 \mathrm{~b}$ for $\mathrm{SAl}$ and SAc, respectively.

As can be seen from Figure $5 \mathrm{a}$ and previously confirmed by the ANOVA analysis (Tables 6 and 7), only the [SAl]/[Sn] molar ratio variable showed a statistically significant influence on the functionalization of PLA. On the other hand, from Figure $5 b$, a different situation is observed since both dependent variables ([SAc] $/[\mathrm{Sn}]$ and $[\mathrm{L}] /[\mathrm{Sn}]$ molar ratios) showed statistically significant influence on the functionalization of PLA. However, the $[\mathrm{SAc}] /[\mathrm{Sn}]$ molar ratio showed more influence than $[\mathrm{SAl}] /[\mathrm{Sn}]$ molar ratio

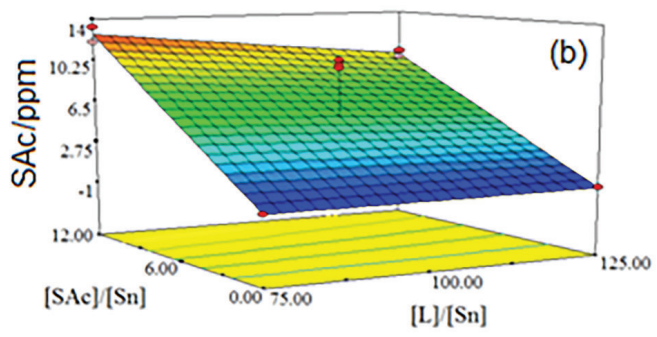

Figure 4. Lactide/catalyst and co-initiator/catalyst molar ratio surface and contour of predicted functionalization ratio for (a) aldehyde and (b) carboxylic acid as co-initiators. 
(a)

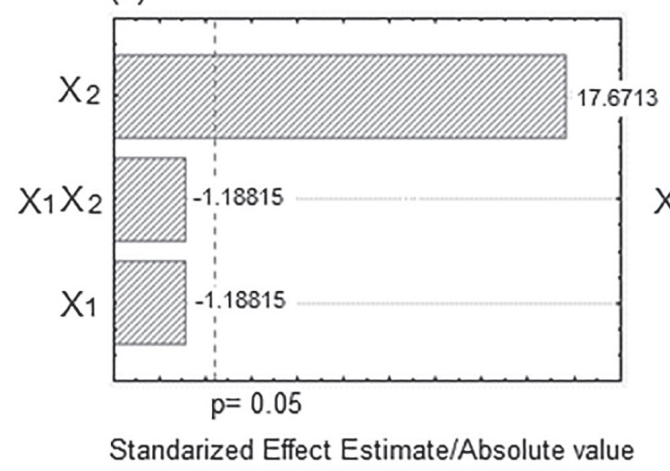

(b)

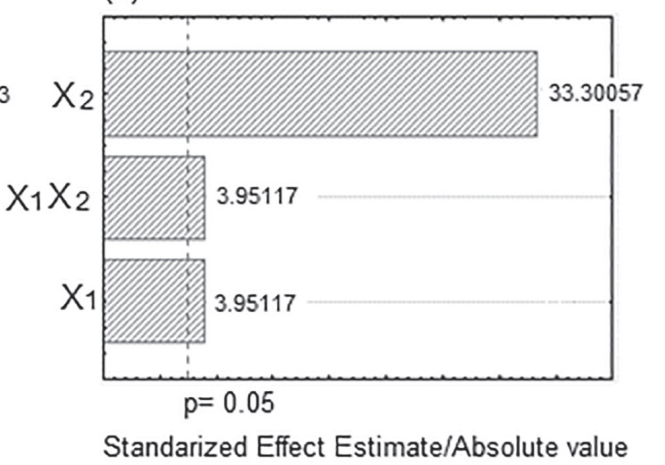

Figure 5. Pareto chart of lactide/catalyst, co-initiator/catalyst molar ratio and standardized effect on the PLA functionalization for (a) aldehyde (MS pure error $=0.2229444)$ and $(b)$ carboxylic acid (MS pure error $=0.229175)$ as co-initiators.
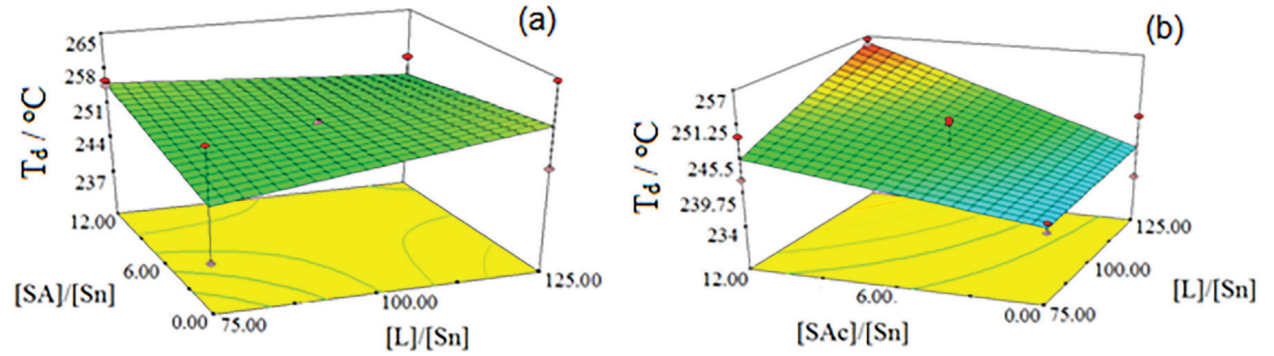

Figure 6. Lactide/catalyst and co-initiator/catalyst molar ratio surface and contour of predicted temperature of maximum degradation rate $\left(T_{d}\right)$ for $(a)$ aldehyde and (b) carboxylic acid end functionalized PLA.

on PLA carboxylic acid functionalization. Probably due to the fact that aromatic aldehyde has a higher inductive effect than aromatic carboxyl group, making the phenolic hydroxyl group of SAl less reactive than in SAc. Finally, it was observed that, the interaction of both dependent variables showed statistically significant influence on the response variable of carboxylic acid functionalization. This result was also confirmed by the ANOVA study.

Thermal characterization of all functionalized PLA synthesized by ROP showed that lactide/catalyst and co-initiator/catalyst molar ratios had a slight influence on its thermal properties. Results of TGA analyses are shown in Figures 6a and 6b.

As can be seen from Figure $6 \mathrm{a},[\mathrm{SAl}] /[\mathrm{Sn}]$ and $[\mathrm{L}] /[\mathrm{Sn}]$ molar ratios did not show a marked influence on the temperature of maximum degradation rate $\left(\mathrm{T}_{\mathrm{d}}\right)$ of the aldehyde end functionalized PLA. On the contrary, $[\mathrm{SAc}] /[\mathrm{Sn}]$ and $[\mathrm{L}] /[\mathrm{Sn}]$ molar ratio showed to have an influence on $T_{d}$ of the carboxylic acid end functionalized PLA. Therefore, more change of $\mathrm{T}_{\mathrm{d}}$ was observed at $[\mathrm{SAc}] /[\mathrm{Sn}]$ molar ratio of $12 / 1$ and $[\mathrm{L}] /[\mathrm{Sn}]$ molar ratio of 75/1 (Figure 6b). These results are probably due to the presence of interactions established by the carboxylic acid end functional group with polymer chains. These results agree with those reported by literature in end functionalization of PLA with maleic anhydride. ${ }^{34}$
Statistically significant influence of [SAc]/[Sn] and [L]/[Sn] molar ratios on $\mathrm{T}_{\mathrm{d}}$ of carboxylic acid end functionalized PLA was evaluated by the Pareto chart (Figure 7).

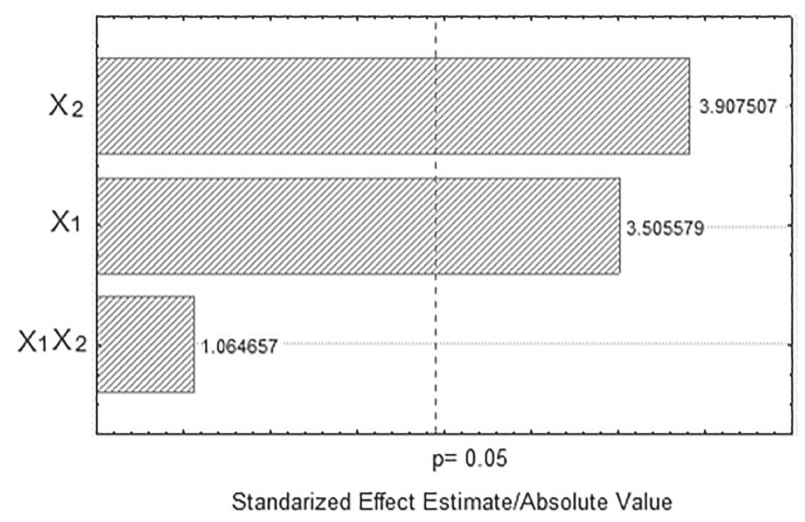

Figure 7. Pareto chart of the influence of $[\mathrm{SAc}] /[\mathrm{Sn}]$ and $[\mathrm{L}] /[\mathrm{Sn}]$ molar ratios on the temperature of maximum degradation rate $\left(\mathrm{T}_{\mathrm{d}}\right)$ of carboxylic acid end functionalized PLA (MS pure error of 9.806492).

As can be seen from Figure 7, [SAc]/[Sn] and [L]/[Sn] molar ratios showed a statistically significant influence on $\mathrm{T}_{\mathrm{d}}$ of the carboxylic acid end functionalized PLA. However, the interaction of both independent variables $\left(\mathrm{X}_{1} \mathrm{X}_{2}\right)$ did not have a significant effect on this response variable.

DSC traces of aldehyde and carboxylic acid end functionalized PLA are shown in Figures 8a and 8b, 
respectively. As shown in the figures, the end functionalized PLA presented slightly lower values of $T_{g}$ and $T_{m}$ than the unfunctionalized PLA. Consequently, utilization of both co-initiators has a moderate impact on the thermal properties of these PLA. Figures $9 \mathrm{a}$ and $9 \mathrm{~b}$ show the statistical analyses of these results. Despite of the slight changes of $\mathrm{T}_{\mathrm{g}}$ and $\mathrm{T}_{\mathrm{m}}$, Pareto chart shows that the influence of co-initiator/catalyst and lactide/catalyst molar ratios were not statistically significant.

From Figure 9, we can also see that the co-initiator/ catalyst molar ratio dependent variable has more effect on the thermal properties of the aldehyde end functionalized PLA than the lactide/catalyst molar ratio variable. However, for carboxylic acid functionalization, the interaction of both dependent variables has more effect on this response variable.

Degree of crystallinity of aldehyde or carboxylic acid end functionalized PLA was also assessed by the influence of the co-initiator/catalyst and lactide/catalyst molar ratios. Results are shown in Figures 10a and 10b.

As shown in Figure 10a, [SAl]/[Sn] and [L]/[Sn] molar ratios showed almost no influence on the degree of crystallinity $\left(\mathrm{X}_{\mathrm{c}}\right)$ of the aldehyde end functionalized PLA. However, more changes of crystallinity were observed at levels of $[\mathrm{L}] /[\mathrm{Sn}]$ molar ratio of $125 / 1$ and $[\mathrm{SAc}] /[\mathrm{Sn}]$ molar ratio of 12/1 (Figure 10b). The presence of carboxylic acid group at the end of polymer backbone could make possible the occurrence of different molecular interactions,
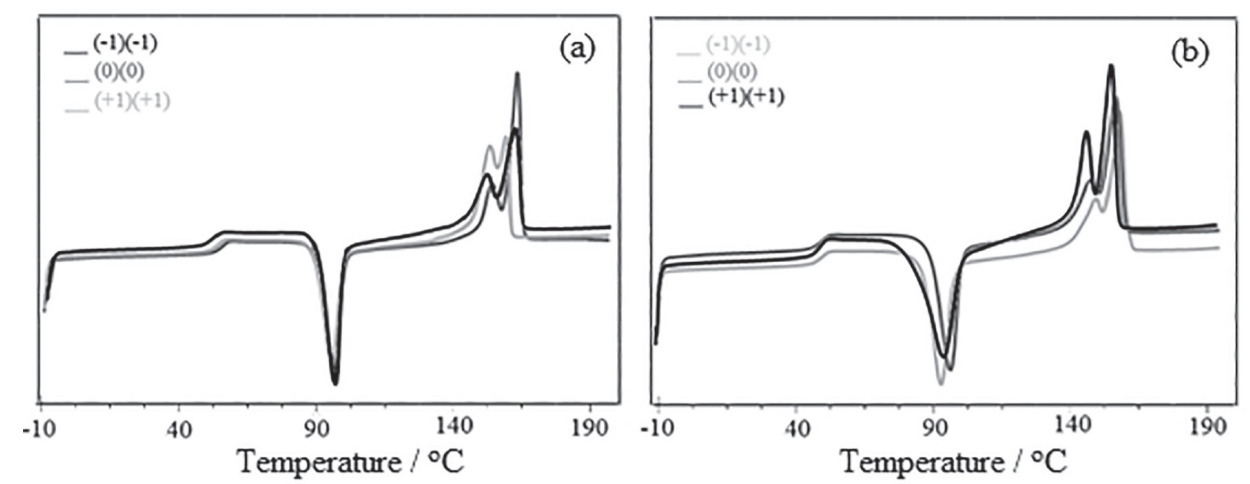

Figure 8. DSC traces of (a) aldehyde and (b) carboxylic acid end functionalized PLA.

(a)

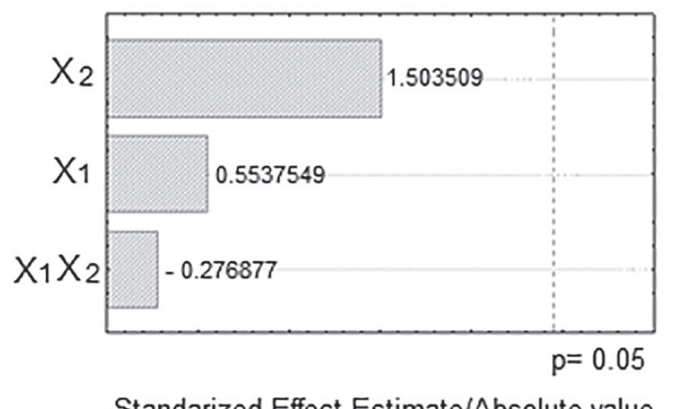

(b)

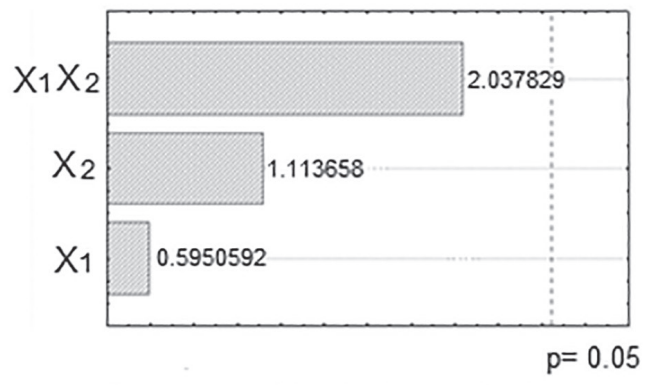

Standarized Effect Estimate/Absolute value

Figure 9. Pareto chart of the influence of $[\mathrm{SAc}] /[\mathrm{Sn}]$ and $[\mathrm{L}] /[\mathrm{Sn}]$ molar ratios on the temperature of maximum degradation rate $\left(\mathrm{T}_{\mathrm{d}}\right)$ of the $(\mathrm{a})$ aldehyde end functionalized PLA (MS pure error $=1.131086$ ) and $(\mathrm{b})$ carboxylic acid end functionalized PLA (MS pure error $=4.823828$ ).

(a)

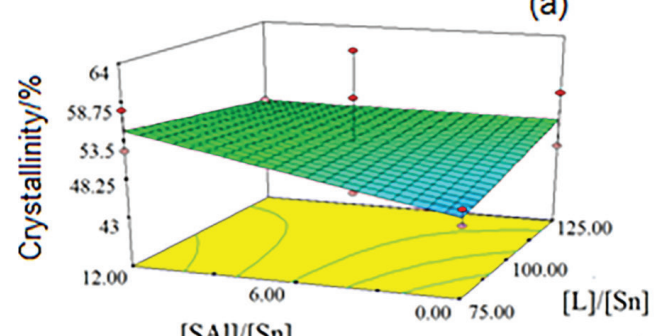

[SAl]/[Sn]

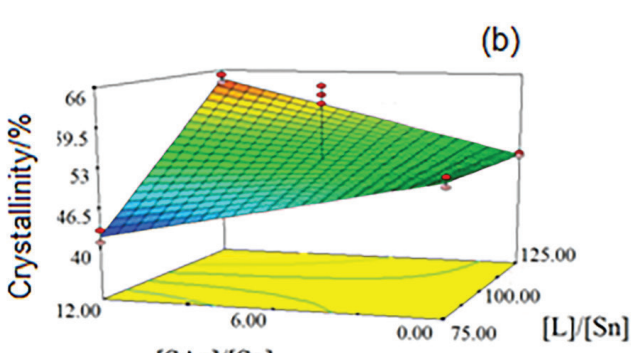

$[\mathrm{SAc}] /[\mathrm{Sn}]$

Figure 10. Lactide/catalyst and co-initiator/catalyst molar ratios surfaces and contour of predicted crystallinity (\%): (a) aldehyde and (b) carboxylic acid end functionalized PLA. 
which could change the crystallization behavior of these functionalized PLA. However, $[\mathrm{L}] /[\mathrm{Sn}]$ ratio was the dependent variable with major influence on this response variable. These results are in agreement with previous reports on thermal characterization of end functionalized PLA. ${ }^{35,36}$

Statistically significant influence of $[\mathrm{SAl}] /[\mathrm{Sn}]$, $[\mathrm{SAc}] /[\mathrm{Sn}]$ and $[\mathrm{L}] /[\mathrm{Sn}]$ molar ratios on the degree of crystallinity was also evaluated by Pareto chart (Figure S1 in the Supplementary Information (SI) section). The influence of $[\mathrm{SAl}] /[\mathrm{Sn}]$ and $[\mathrm{L}] /[\mathrm{Sn}]$ on the crystallinity of the aldehyde end functionalized PLA was statistically non-significant. On the other hand, interaction of both dependent variables showed statistically significant influence on the degree of crystallinity for carboxylic acid end functionalized PLA as well as the dependent variable of $[\mathrm{SAc}] /[\mathrm{Sn}]$ molar ratio (Figure S1b in the SI section).

The influence of $[\mathrm{L}] /[\mathrm{Sn}]$, $[\mathrm{SAl}] /[\mathrm{Sn}]$ and $[\mathrm{SAc}] /[\mathrm{Sn}]$ on the molecular weight of the functionalized PLA was also investigated by analyzing GPC data in terms of response surface plots (Figures 11a and 11b).

Figures $11 \mathrm{a}$ and $11 \mathrm{~b}$ illustrate that highest values of molecular weight were achieved with the increase in lactide/catalyst molar ratio. Hence maximum value of molecular weight $(\mathrm{Mw})$ was achieved for lactide/ catalyst molar ratio of 125/1 in both experimental designs. Both co-initiators/catalyst molar ratios ([SAl]/[Sn] and $[\mathrm{SAc}] /[\mathrm{Sn}])$ showed the same behavior, i.e., they showed no effect on Mw. Considering the mechanism of ROP previously described, higher lactide/catalyst molar ratio increases the probability of coordination between lactide and catalyst agent and the synthesis of polymers with higher molecular weight. ${ }^{7,37}$ However, some impurities such as lactic acid and other hydroxyl impurities are also able to coordinate with the catalyst and they have influence on the final polymer molecular weight. ${ }^{29,38-41}$ In our study these impurities were not assessed.

Statistically significant influence of lactide/catalyst and co-initiator/catalyst ratios on the $\mathrm{Mw}$ was evaluated by the Pareto chart (Figures S2a and S2b in the SI section). Results obtained from Pareto chart confirmed that the effect of lactide/catalyst molar ratio on $\mathrm{Mw}$ was statistically significant. On the other hand, this influence was independent on the co-initiator/catalyst molar ratio used in the ROP. Therefore, the co-initiator/catalyst molar ratio was statistically non-significant on $\mathrm{Mw}$.

\section{Conclusions}

Tin initiated ring opening polymerization was used to synthesize PLA with aldehyde and carboxylic acid end groups by using salicyl aldehyde and salicylic acid as co-initiators. Identification of the functional groups linked to the end of PLA backbones was elucidated by UV-Vis and ${ }^{1} \mathrm{H}$ NMR techniques. The two experimental designs used in this work made possible the identification of the best ROP condition to assure maximum aldehyde and carboxylic acid functionalization of PLA. Besides both experimental designs allow to determine the influence of the $[$ lactide $] /[\mathrm{Sn}],[\mathrm{SAl}] /[\mathrm{Sn}]$ and $[\mathrm{SAc}] /[\mathrm{Sn}]$ molar ratios on the thermal properties and molecular weights of the functionalized PLA. Although [lactide]/[Sn] molar ratio shows the expected behavior regarding to molecular weight, i.e., the $\mathrm{Mw}$ is higher as [lactide]/[Sn] increases, co-initiators/catalyst molar ratios ([SAl]/[Sn] and $[\mathrm{SAc}] /[\mathrm{Sn}])$ showed no statistically significant effect on Mw. The content of functional end groups in the polymer was dramatically influenced by these ratios, that increased the aldehyde and carboxylic acid content in the polymers when they were increased. We found that the influence of co-initiators/catalyst ratios on the degradation temperature $\left(\mathrm{T}_{\mathrm{d}}\right)$ of the polymers has different behavior, the carboxylic acid end groups influenced much more the $T_{d}$ decrease than the aldehyde functionality. Both salicyl aldehyde and salicylic acid were quite useful for the synthesis of PLA containing aldehyde and carboxylic acid functional end groups. These functionalized PLA could be potentially useful for the synthesis and design of some different active biomaterial for medical applications.
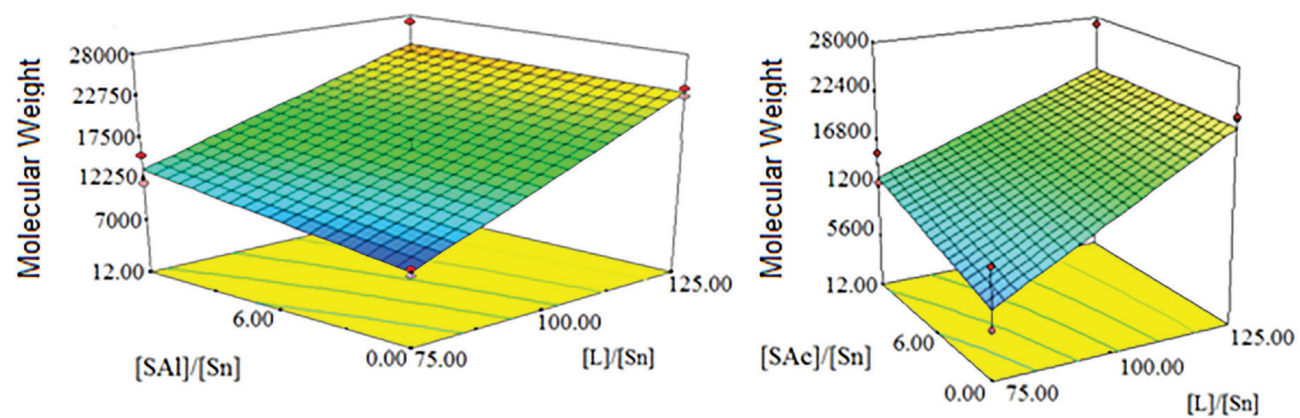

Figure 11. Response surface plots of molecular weight versus lactide/catalyst and co-initiator/catalyst of (a) aldehyde and (b) carboxylic acid end functionalized PLA. 


\section{Supplementary Information}

Supplementary data are available free of charge at http://jbcs.sbq.org.br as PDF file.

\section{Acknowledgments}

Authors thank the Brazilian agencies CAPES (Project MES Cuba No. 133-11), FAPERJ (CNEE-26/201.340/2014) and CNPq (310917/2014-0) for the financial support.

\section{References}

1. Achmad, F.; Yamane, K.; Quan, S.; Kokugan, T.; Chem. Eng. J. 2009, 151, 342.

2. Carrasco, F.; Pagès, P.; Gámez-Pérez, J.; Santana, O. O.; Maspoch, M. L.; Polym. Degrad. Stab. 2010, 95, 116.

3. Selukar, B. S.; Parwe, S. P.; Mohite, K. K.; Garnaik, B.; Adv. Mater. Lett. 2012, 3, 161 .

4. Drumright, R. E.; Gruber, P. R.; Henton, D. E.; Adv. Mater. 2000, 12, 1841 .

5. Albertsson, A. C.; Varma, I. K.; Biomacromolecules 2003, 4, 1466.

6. Cabaret, D. O.; Vaca, B. M.; Bourissou, D.; Chem. Rev. 2004, 104, 6147.

7. Endo, T. In Handbook of Ring-Opening Polymerization; Dubois, P.; Coulembier, O.; Raquez, J. M., eds.; Wiley-VCH: Weinheim, Germany, 2009, p. 53.

8. Motta, A. C.; Duek, E. A. R.; Matéria 2006, 11, 340.

9. Riley, T.; Stolnik, S.; Heald, C. R.; Xiong, C. D.; Garnett, M. C.; Illum, L.; Davis, S. S.; Purkiss, S. C.; Barlow, R. J.; Gellert, P. R.; Langmuir 2001, 17, 3168.

10. Li, J.; Rothstein, S. N.; Little, S. R.; Edenborn, H. M.; Meyer, T. Y.; J. Am. Chem. Soc. 2012, 134, 16352.

11. Tu, F.; Lee, D.; Langmuir 2012, 28, 9944.

12. Selukar, B. S.; Parwe, S. P.; Mohite, K. K.; Garnaik, B.; Adv. Mater. Lett. 2012, 3, 161.

13. Lunt, J.; Polym. Degrad. Stab. 1998, 59, 145.

14. Bendix, D.; Polym. Degrad. Stab. 1998, 59, 129.

15. Bailey, W. J. In Ring-Opening Polymerization - ACS Symposium Series; McGrath, J. E., ed.; American Chemical Society: USA, 1985, p. 47.

16. Garlotta, D.; J. Polym. Environ. 2001, 9, 63.

17. Kricheldorf, H. R.; Sanders, I. K.; Boettcher, C.; Polymer 1995, 36, 1253.

18. Hseih, H. L.; Wang, I. W. In Ring-Opening Polymerization - ACS Symposium Series; McGrath, J. E., ed.; American Chemical Society: USA, 1985, p. 161.

19. Xiao, L.; Wang, B.; Yang, G.; Gauthier, M. In Biomedical Science, Engineering and Technology; Ghista, D. N., ed.; InTech: Rijeka, Croatia, 2012, p. 247.
20. Inkinen, S.; Hakkarainen, M.; Albertsson, A. C.; Sodergard, A.; Biomacromolecules 2011, 12, 523.

21. Icart, L. P.; Santos, E. R. F.; Pereira, E. D.; Ferreira, S. R.; Saez, V.; Ramon, J. A.; Nele, M.; Pinto, J. C. S.; Toledo, R. D.; eXPRESS Polym. Lett. 2016, 10, 188.

22. Icart, L. P.; Fernandes, E.; Agüero, L.; Ramón, J.; Zaldivar, D.; Dias, M. L.; J. Appl. Polym. Sci. 2016, 133, 42994.

23. Hamad, K.; Kaseem, M.; Yang, H. W.; Deri, F.; Ko, Y. G.; eXPRESS Polym. Lett. 2015, 9, 435.

24. Lucke, A.; Fustella, E.; Teßmar, J.; Gazzaniga, A.; Göpferich, A.; J. Controlled Release 2002, 80, 157.

25. Sarasua, J. R.; Rodríguez, N. L.; Arraiza, A. L.; Meaurio, E.; Macromolecules 2005, 38, 8362.

26. Kohn, F. E.; Van Ommen, J. G.; Feijen, J.; Eur. Polym. J. 1983, 19, 1081.

27. Stridsberg, K.; Ryner, M.; Albertsson, A.-C. In Advanced Polymer Science; Albertsson, A. C., ed.; Springer: Berlin/ Heidelberg, Germany, 2002, p. 41.

28. Báez, J. E.; Fernández, A. M.; Iranzo, P. G.; J. Polym. Res. 2011, $18,1137$.

29. Witzke, D. R.; Narayan, R.; Kolstad, J. J.; Macromolecules 1997, 30, 7075.

30. Chisholm, M. H.; Llobet, D. N.; Simonsick, W. J.; Macromolecules 2001, 34, 8851.

31. Eguiburu, J. L.; Berridi, M. F. J.; San Roman, J.; Polymer 1995, $36,173$.

32. Tang, X. C. Z.; Tian, X. Z. H.; Jing, X.; Prog. Polym. Sci. 2012, $37,237$.

33. Ferrari, R.; Yu, Y. C.; Morbidelli, M.; Hutchinson, R. A.; Moscatelli, D.; Macromolecules 2011, 44, 9205.

34. Peng, Z. A.; Peng, X.; J. Am. Chem. Soc. 2001, 123, 183.

35. Niaounakis, M.; Biopolymers: Processing and Products, $1^{\text {st }}$ ed.; William Andrew: Oxford, UK, 2014.

36. Renard, E.; Barbaud, C.; Langlois, V.; Guérin, P. In Biodegradable Polymers and Plastics; Chiellini, E.; Solaro, R., eds.; Springer: USA, 2003, p. 301.

37. Cabaret, O. D.; Vaca, B. M.; Bourissou, D. In Handbook of Ring-Opening Polymerization; Dubois, P.; Coulembier, O.; Raquez, J. M., eds.; Wiley-VCH: Weinheim, Germany, 2009, p. 255.

38. Codari, F.; Moscatelli, D.; Storti, G.; Morbidelli, M.; Macromol. Mater. Eng. 2010, 295, 58.

39. Espartero, J. L.; Rashkov, I.; Manolova, N.; Vert, M.; Macromolecules 1996, 29, 3535.

40. Fu, C.; Liu, Z.; Polymer 2008, 49, 461.

41. Hyon, S. H.; Jamshidi, K.; Ikada, Y.; Biomaterials 1997, 18, 1503.

Submitted: March 5, 2017

Published online: June 26, 2017 